\title{
Ginkgotoxin Induced Seizure Caused by Vitamin B6 Deficiency
}

\section{Case Report}

Journal of Epilepsy Research pISSN 2233-6249 / eISSN 2233-6257

Received June 30, 2015

Accepted August 22, 2015

Corresponding author: Sook Young Roh Department of Neurology, Bundang Jesaeng General Hospital, 20 Seohyeon-ro 180beon-gil, Bundang-gu, Seongnam 13590, Korea

Tel. $+82-31-779-0216$

Fax. +82-31-779-0897

E-mail; syrohnu@dmc.or.kr

\author{
Hyun-soon Jang, Sook Young Roh, Eun Hye Jeong, Byung-Su Kim, Mun Kyung Sunwoo \\ Department of Neurology, Bundang Jesaeng General Hospital, Seongnam, Korea
}

Although ginkgo is commonly used as an alternative treatment for memory loss, Alzheimer's dementia and peripheral circulatory disturbances, it is also known to cause neuronal symptoms due to ginkgotoxin (4'-methoxypyridoxine or B6 antivitamin). We experienced a case of a 51-year-old female patient with generalized tonic clonic seizure and postictal confusion after eating large amounts of ginkgo nuts. Blood vitamin B6 level was decreased. After conservative treatment and pyridoxine medication, her mental symptoms were resolved completely and no seizures recurred. (2015;5:104-106)

Key words: Ginkgotoxin, Seizure, Vitamin B6 deficiency

\section{Introduction}

Ginkgo biloba is widely used for an alternative treatment for diverse neurological symptoms such as memory decline, peripheral circulatory disturbance and dizziness because of evidence that it improves cerebral blood flow and confers neuroprotective effects against cerebral ischemic injury. ${ }^{1}$ But it is also known as neurotoxin (ginkgotoxin) that possibly triggers vomiting and epileptic convulsions even though the mechanisms are unclear. ${ }^{2}$ Here we report the case of 51 -year-old female patient with a generalized tonic clonic seizure induced by ginkgotoxin and vitamin B6 deficiency.

\section{Case}

A

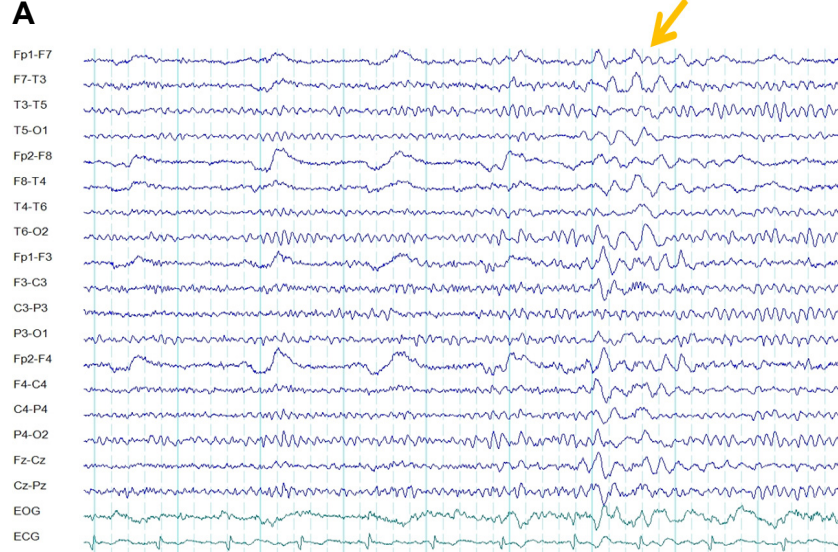

A 51-year-old woman without underlying disease presented with generalized tonic clonic seizure for several minutes followed by dizziness and generalized weakness. There was no history of recent head trauma or infectious disease. She did not have smoking, alcohol drinking and specific family history. By obtaining her detailed history, we determined that she had overconsumed large amounts of ginkgo nuts $1 \mathrm{~kg}$ for 1 hour. About half a day later, the seizure occurred.

At the time of emergency room visit, her vital signs were blood pressure $121 / 81 \mathrm{mmHg}$, pulse rates $76 \mathrm{bpm}$, respiratory rates 18 bpm, body temperature $36.2^{\circ} \mathrm{C}$ and $\mathrm{O}_{2}$ saturation $98 \%$. Neurologic examination showed normal findings except for drowsiness. Blood tests revealed slightly elevated white blood cell $(10,600 / \mathrm{mL})$ and normal ranges of hemoglobin ( $12.6 \mathrm{~g} / \mathrm{dL})$, platelet $(188,000 / \mathrm{uL})$ and C-reactive protein $(0.03 \mathrm{mg} / \mathrm{dL})$. Arterial blood gas analysis indicated

Figure 1. EEG findings. (A) Initial nasopharyngeal EEG showed intermittent generalized slowing (arrow) and there is no epileptiform discharge. (B) Follow up EEG showed normal EEG finding. EEG, electroencephalography. 
metabolic acidosis ( $\mathrm{pH} 7.337, \mathrm{pCO}_{2} 38.7 \mathrm{mmHg}, \mathrm{pO}_{2} 36.7 \mathrm{mmHg}$, $\mathrm{HCO}_{3} 20.3 \mathrm{mmol} / \mathrm{L}$, base excess $-5.50 \mathrm{mmol} / \mathrm{L}$ and $\mathrm{O}_{2}$ saturation $68.9 \%$ ) which became normalized after adequate hydration and oxygenation. Serum electrolyte and chemistry levels were normal (sodium $138 \mathrm{mmol} / \mathrm{L}$, potassium $4.0 \mathrm{mmo} / \mathrm{L}$, aspartate aminotransferase $44 \mathrm{IU} / \mathrm{L}$, alanine aminotransferase $22 \mathrm{IU} / \mathrm{L}$, blood urea nitrogen 14.5 $\mathrm{mg} / \mathrm{dL}$, and creatinine $1.06 \mathrm{mg} / \mathrm{dL}$ ) and muscle enzyme levels were mildly increased (creatine kinase $256 \mathrm{IU} / \mathrm{L}$, lactate dehydrogenase $540 \mathrm{IU} / \mathrm{L}$ ). Blood vitamin B6 level was decreased (2.2 ug/L, normal range: 5.0-50.0 ug/L). The electrocardiography and brain magnetic resonance imaging findings were normal. Initial electroencephalography (EEG) revealed intermittent generalized slow waves, but no epileptiform discharges were observed (Fig. 1A). Cerebrospinal fluid (CSF) study was performed due to prolonged decreased mentality and her CSF analysis showed normal findings (pressure $14 \mathrm{cmH}_{2} \mathrm{O}$, red blood cell $0 / \mathrm{mL}$, white blood cell $2 / \mathrm{mL}$, polymorphonuclear cell $0 \%$, lymphocyte $0 \%$, monocyte $0 \%$, CSF glucose $83 \mathrm{mg} / \mathrm{dL}$, blood glucose $128 \mathrm{mg} / \mathrm{dL}$ and protein $15.0 \mathrm{mg} / \mathrm{dL}$ ).

After admission, she was taken to supportive management without anticonvulsants medication and received $50 \mathrm{mg}$ oral pyridoxine daily. No more seizures recurred and her mental function was resolved completely. Three weeks later, her blood vitamin B6 level was within normal range (12.1 ug/L), and EEG findings returned to normal (Fig. 1B).

\section{Discussion}

Ginkgo biloba, which is extracted from the ginkgo leaves and seeds, is used to treat a diverse disease, including memory loss, cerebral insufficiency, cough, asthma, neurogenic bladder and alcoholism. It is therefore commonly consumed as a health supplement in Europe and America as well as Asian countries. ${ }^{1}$ The postulated mechanisms of action of Ginkgo bilobainclude increased blood flow, antagonism of platelet activating factor and prevention of membrane damage caused by free radicals. ${ }^{2}$

However, during the extraction process of ginkgo leaves, ginkgotoxin, known as 4'-0-methylpyridoxine (4'-MPN) is introduced and causes several neurotoxic symptoms. ${ }^{3} 4^{\prime}-\mathrm{MPN}$ is considered to be an antivitamin B6 compound because it is structurally related to vitamin B6 and interferes with biosynthesis, metabolism or function of vita$\min B 6^{4}$

Vitamin B6 participates in many enzymatic reactions including amino acid metabolisms and reactions involved in the synthesis of

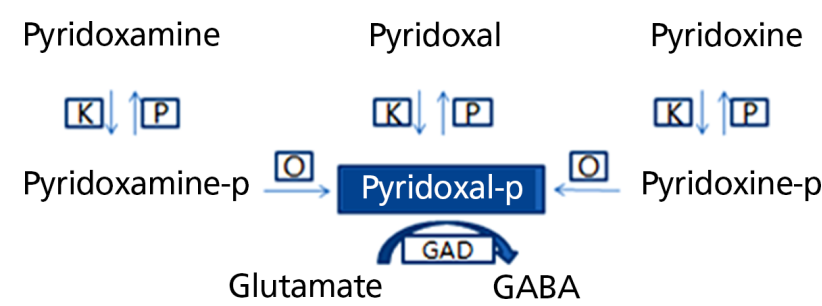

Figure 2. Metabolism of vitamin $B 6 . K$, pyridoxal kinase; $O$, pyridoxine (pyridoxamine) 5'-phosphate oxidase; $P$, phosphatase; GAD, glutamate decarboxylase. GABA, gamma-aminobutyric acid.

neurotransmitters. ${ }^{4}$ It occurs in several forms, which consists of pyridoxine, pyridoxamine, and pyridoxal and their $5^{\prime}$-phosphates. ${ }^{5}$ All three analogues of the $\mathrm{B} 6$ vitamers are phosphorylated by pyridoxal kinase, and the 5'-phosphates of pyridoxamine and pyridoxine are subsequently oxidized by pyridoxine $5^{\prime}$-phosphate oxidase to yield pyridoxal-5'-phosphate (PLP), which is a physiologically active form of vitamin B6 and a good indicator of vitamin B6 status in the body. ${ }^{5}$ PLP is required as a cofactor in the formation of gamma-aminobutyric acid (GABA), the main inhibitory neurotransmitter, from glutamate, the main excitatory neurotransmitter, by glutamate decarboxylase (Fig. 2). ${ }^{4}$

Although the mechanisms of $4^{\prime}$-MPN induced seizure has not been clarified, $4^{\prime}$-MPN is responsible for epilepsy by an imbalance between amount of glutamate and GABA. ${ }^{6} 4^{\prime}$-MPN has a high affinity to pyridoxal kinase and interfere with the important enzyme for PLP production, therby inhibits GABA synthesis and the risk for developing seizures is raised. ${ }^{4}$ Recent in vivo study demonstrated that plasma PLP concentration significantly decreased from 2 to 120 minutes after $4^{\prime}$-MPN administration. ${ }^{6}$ This data indicates that 4'-MPN administration could induce vitamin B6 deficiency. In our case, we had no blood or urine level of 4'-MPN, however, decreased blood vitamin B6 level was the reason for subsequent epileptic convulsions after overconsumption of ginkgo nuts.

The treatment strategy of ginkgotoxin induced seizures is a prompt antiepileptic drug medication or pyridoxine supplementation for support of GABA synthesis. ${ }^{7.8}$ Vitamin B6 administration can abolish 4'-MPN induced seizures and the symptoms associated with Ginkgo bilobaseeds poisoning. Although the recommended dosages of pyridoxine have not been reported especially in adults, we prescribed oral pyridoxine $50 \mathrm{mg}$ daily with the supportive management taking pyridoxine toxicity into consideration. ${ }^{9}$

Our case demonstrated a decreased vitamin B6 level in the plasma after ginkgo nuts overconsumption and inducing seizure. Although ginkgo nuts are known as familiar health foods and are commonly 
ingested, more care is needed especially in the elderly because ginkgotoxin is also a neurotoxin capable of inducing epileptic convulsions.

\section{References}

1. Singh B, Kaur P, Gopichand, Singh RD, Ahuja PS. Biology and chemistry of Ginkgo biloba. Fitoterapia 2008;79:401-18.

2. Granger AS. Ginkgo biloba precipitating epileptic seizures. Age and Ageing 2001;30:523-5.

3. Wada K, Ishigaki S, Ueda K, Sakata M, Haga M. An antivitamin B6, 4'-methoxypyridoxine, from the seed of Ginkgo biloba L. Chem Pharm Bull 1985;33:3555-7.

4. Kastner U, Hallmen C, Wiese M, Leistner E, Drewke C. The human pyridoxal kinase, a plausible target for ginkgotoxin from Ginkgo biloba.
FEBS / 2007;274:1036-45.

5. Merrill Jr AH, Henderson JM, Wang E, McDonald BW, Millikan WJ. Metabolism of vitamin B-6 by human liver. J Nutr 1984;114:1664-74.

6. Kobayashi D, Yoshimura T, Johno A, Ishikawa M, Sasaki K, Wada K. Decreased in pyridoxal-5'-phosphate concentration and increased in pyridoxal concentration in rat plasma by 4'-0-methylpyridoxine administration. Nutr Res 2015;35:637-42.

7. Seo IK, Park JK, Choi YI, et al. Status Epilepticus in a Patient With Ginkgo Nuts Intoxication. J Korean Neurol Assoc 2011;29:124-6.

8. Mizuno N, Kawakami K, Morita E. Competitive inhibition between 4 '-substituted pyridoxine analogues and pyridoxal for pyridoxal kinase from mouse brain. J Nutr Sci Vitaminol 1980;26:535-43.

9. Parry GJ, Bredesen DE. Seonsory neuropathy with low-dose pyridoxine. Neurology 1985;35:1466-8. 